\title{
Imunocitomonitorização em pacientes transplantados cardíacos
}

\author{
Ricardo MANRIQUE*, Eliete C. CARVALHO*
}

RBCCV 44205-107

MANRIQUE, R. \& CARVALHO, E. C. - Imunocitomonitorização em pacientes transplantados cardíacos. Rev. Bras. Cir. Cardiovasc., 5(1): 54-60, 1990.

RESUMO: A técnica de Imunocitomonitorização (CIM - Cytological and Immunologic Monitoring), fundamenta-se na avaliação de mudanças nas subpopulaçōes de linfócitos e seus precursores celulares, durante o processo rejeição aguda. O método avalia a ativação precoce pela contagem do número de: linfócitos ativados, linfoblastos e prolinfócitos (aqui chamados em conjunto de linfócitos ativos), quando esses se apresentam acima do limite superior normal. Utilizamos essa técnica para seguimento e controle da atividade da imunologia celular em 9 pacientes transplantados cardiacos. Também foram submetidos ao CIM para verificar a faixa de normalidade de ativação linfocitica 20 voluntários normais e cinco pacientes candidatos ao transplante cardíaco. Ambos os grupos não tinham antecedentes de quadro de infecçăo ou alteraçăo imunológica. Para obtenção do controle positivo, testamos 10 pacientes com infecção bacteriana ou viral, previamente diagnosticados por exames bacterianos e/ou sorológicos. Foram observados valores de 1,8\% de linfócitos ativos nos individuos normais e 3,2\% nos candidatos ao transplante cardiaco. Dos 63 testes realizados nos transplantados cardiacos, quatro deles se mostraram positivos, onde três desses tratavam-se de casos de infecçāo e um confirmado como processo de rejeiçāo aguda em evoluçăo. $O$ tempo médio necessário para a realização da CIM foi de aproximadamente duas horas. A técnica utiliza mostrou-se valiosa no reconhecimento imunológico dos pacientes transplantados cardiacos, pela sua sensibilidade diagnóstica, baixo custo e rapidez.

DESCRITORES: imunocitomonitorização em transplante cardiaco; transplante cardiaco, humano, imunocitomonitorização.

\section{INTRODUÇÃO}

A manutenção de um órgão transplantado depende de uma adequada terapia imunossupressora. As consequeências de uma excessiva depressão imunológica induzida iatrogenicamente são quadros de superinfecção. Por outro lado, a deficiência terapêutica é acompanhada de crise de rejeição. Requerendo, portanto, controle da intensidade da imunossupressão. As técnicas laboratoriais rotineiras para controle imunológico em transplantados cardíacos eram constituídas pelo estudo da vida média da globulina antilinfocitária ${ }^{3} \mathrm{e}$ a determinação dos níveis de linfócitos " $T$ " medidos pela capacidade de formar rosetas " $E$ " com hemácias de carneiro ${ }^{4}$. A terapia imunossupressora se baseava na utilizaçāo da azatioprina e corticosteróides associados a globulina antilinfocitária de coelho ${ }^{2}$. Com o uso da ciclosporina, essas técnicas tornaram-se irrelevantes e seus resultados, não condizentes com a clínica desses pacientes. A técnica padrão de controle imunológico para transplantados cardíacos passou a ser a biopsia miocárdica ${ }^{3}$; no entanto, por tratar-se de procedimento de caráter invasivo e não excluído de complicaçóes, tem seu uso limitado. Objetivando diagnosticar precocemente crises de rejeiçăo aguda, além de diminuir o número de biopsias, HAMMER et alii ${ }^{8}$ estudaram a presença de linfoblastos e prolinfoblastos em sangue periférico de pacientes submetidos ao transplante cardíaco. Os resultados obtidos indicaram

Trabalho realizado no Instituto Dante Pazzanese de Cardiologia. Săo Paulo, SP, Brasil,

Recebido para publicaçăo em 22 de janeiro de 1990.

- Do Instituto Dante Pazzanese de Cardiologia.

Endereço para separatas: Ricardo Manrique. Av. Dante Pazzanese, 500. Ibirapuera. 04012 São Paulo, SP, Brasil. 
MANRIQUE, R. \& CARVALHO, E. C. - Imunocitomonitorização em pacientes transplantados cardiacos. Rev. Bras. Cir. Cardiovasc., 5(1): 54-60, 1990.

que essas alteraçōes citológicas puderam ser vistas com 1 a 3 dias de antecedência dos resultados histológicos. A sua correlaçăo com o cociente OKT4/OKT8 e outros receptores de membrana, como OKT6 e leucina-2 positivo, permitiu diferenciar quadros de infecção viral ou bacteriana da rejeiçāo. O objetivo deste trabalho é usar os princípios da técnica acima, procedendo a um acompanhamento imunocitológico em transplantados cardíacos nas fases pré e pós-operatória, para determinar o número de linfócitos com características blásticas (prolinfócitos e linfoblastos) e fornecer um diagnóstico não invasivo para crise aguda de rejeição a ser confirmada por biopsia miocárdica.

\section{CASUÍSTICA E MÉTODOS}

\section{Pacientes}

A amostra constituiu-se de 44 pessoas acompanhadas por CIM, de agosto de 1987 a abril de 1988, procedentes de três hospitais. Nove eram pacientes transplantados do coraçăo, sendo oito deles do sexo masculino com idades entre 22 e 53 anos e uma paciente do sexo feminino com oito anos de idade. Cinco eram candidatos ao transplante cardíaco, sendo dois do sexo masculino com idades entre 35 e 39 anos e três do sexo feminino com idades entre 29 e 36 anos. Todos os pacientes transplantados foram tratados no Hospital do Coração da Associação do Sanatório Sírio, de São Paulo. Dez pacientes apresentavam infecção bacteriana ou viral, sendo cinco do sexo feminino com idades entre 34 e 45 anos e cinco do sexo masculino com idades entre 35 e 39 anos, pacientes do Instituto Dante Pazzanese de Cardiologia, de São Paulo. Vinte eram pessoas normais (não sujeitas ao quadro de ativação imunológica): 14 deles do sexo masculino com idades entre 18 e 46 anos e seis do sexo feminino com idades entre 20 e 35 anos, doadores de sangue do Hospital dos Servidores do Estado de São Paulo.

\section{Citomonitorização}

A coleta foi feita por punção venosa, em seringa plástica previamente heparinizada, volume de $5 \mathrm{ml}$. Para separarmos os linfócitos, utilizamos um gradiente de $\mathrm{Fi}$ coll/Hipaque, segundo BOYUM ${ }^{5}$.

O sangue total foi centrifugado a $3.000 \mathrm{rpm}$ por cinco minutos. Desprezamos o liqüido sobrenadante e diluímos o sedimento celular 1:3 em solução fisiológica a 0,85\%. Após ligeira homogeneização, depositamos a amostra sobre a superficie do gradiente com densidade igual a $1.077 \mathrm{~g} / \mathrm{ml}$ e centrifugamos a $1.200 \mathrm{rpm}$ durante $30 \mathrm{minu}-$ tos. Aspiramos a camada de células mononucleares que se concentrou na interface dos líqüidos. Procedemos, a seguir, a duas lavagens em soluçāo fisiológica a 0,85\%

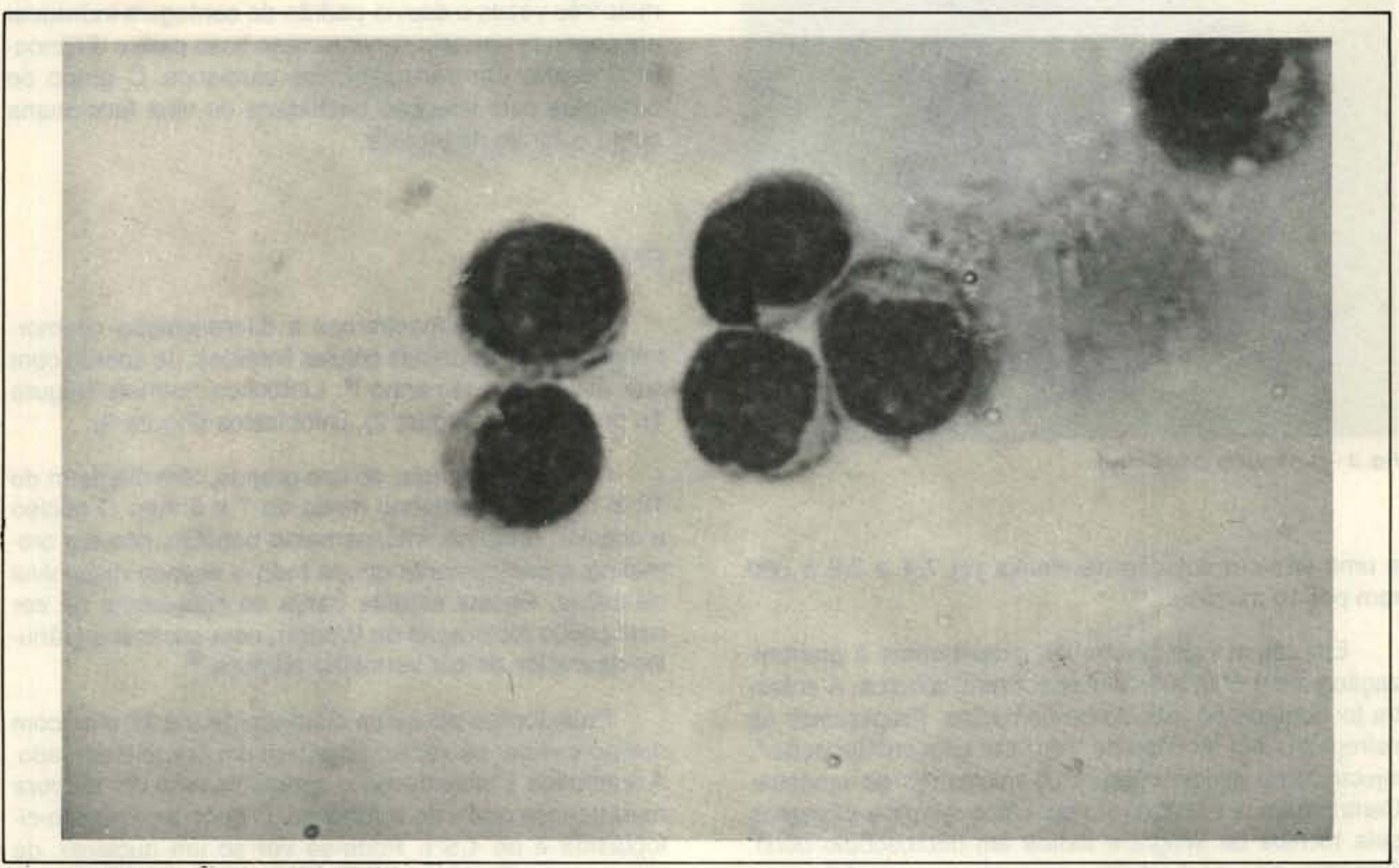

Fig. 1 - Linfocitos normais $(7-9 \mathrm{mml})$. 
MANRIQUE, R. \& CARVALHO, E. C. — Imunocitomonitorização em pacientes transplantados cardiacos. Rev. Bras. Cir. Cardiovasc., $5(1): 54-60,1990$.

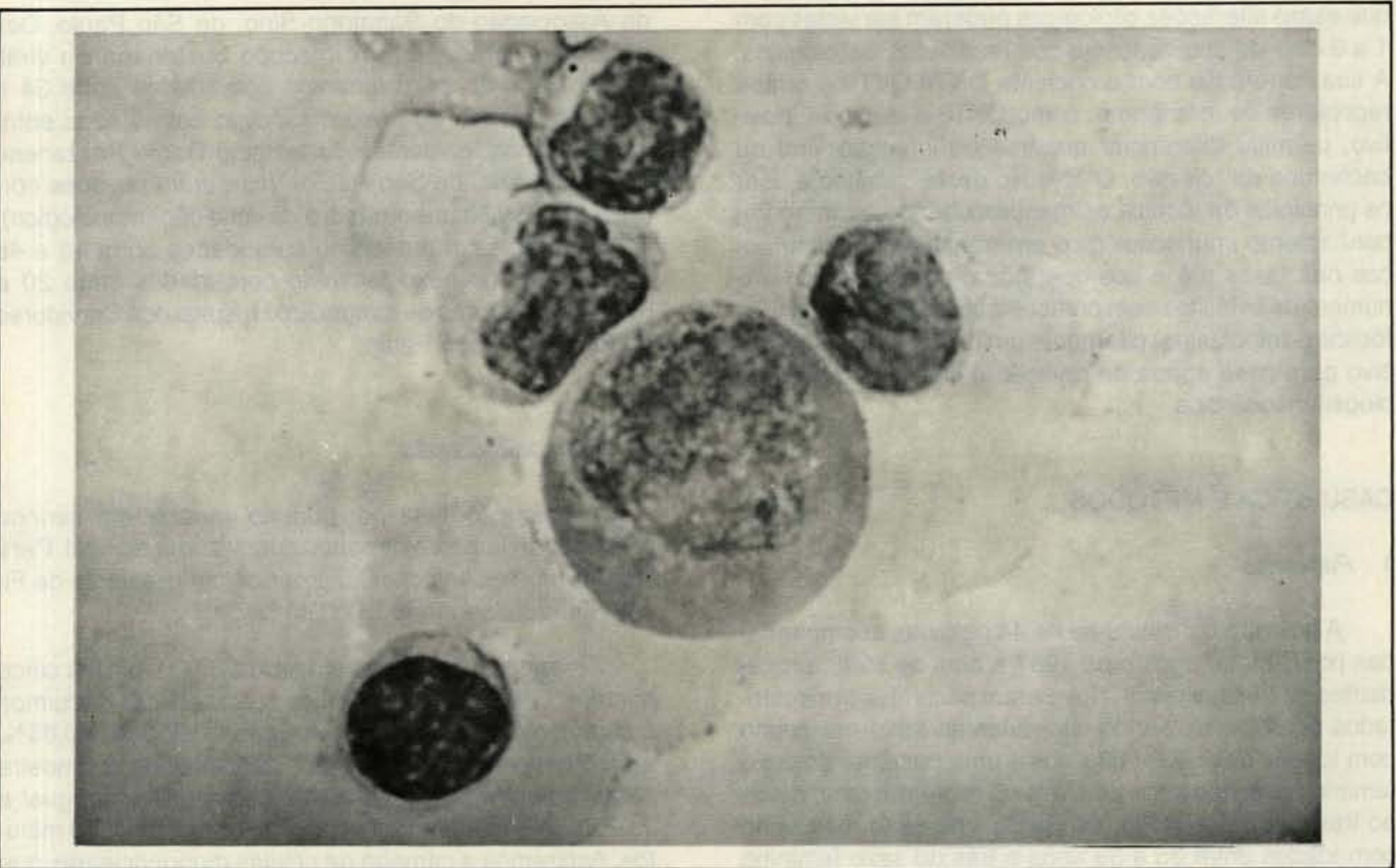

Fig. 2-Prolinfócito (9-12 mml).

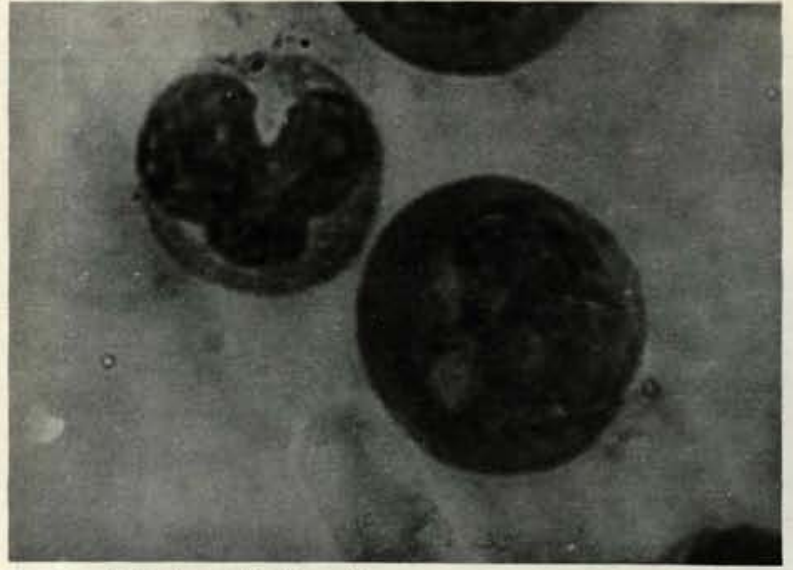

Fig. 3 - Linfoblasto (11-16 mml).

e uma vez em soluçăo de Hanks pH 7.4 a 7.6 a 600 rpm por 10 minutos.

Em câmara de Neubauer, procedemos à padronizaçăo para 1.500 .000 células por $\mathrm{mml}$ cúbicos. A amostra foi contada no retículo de hemácias. Preparamos os esfregaços em lâminas de vidro por citocentrifugação 6 , injetando na citocentrífuga 200 microlitros da amostra. Centrifugamos a $3.000 \mathrm{rpm}$ por cinco minutos. Coramos pela técnica de Wright e lemos em microscópio ótico. Classificamos os linfócitos segundo sua morfologia e basofilia citoplasmática ${ }^{10}$. Estabelecemos que a média mais três vezes o desvio padrão da contagem individual em pessoas normais serviria como base para o diagnóstico positivo em transplantados cardíacos. O grupo de pacientes com infecçăo bacteriana ou viral funcionaria como controle da técnica.

\section{RESULTADOS}

Na Figura 1, mostramos a diferenciação citomorfológica encontrada nas células linfóides, de acordo com sua ativação e tamanho ${ }^{10}$. Linfócitos normais (Figura 1), prolinfócitos (Figura 2), linfoblastos (Figura 3).

Linfócitos normais, do tipo grande, têm diâmetro de 12 a $15 \mathrm{~mm}$, o pequeno mede de 7 a $8 \mathrm{~mm}$. O núcleo é circular, redondo, intensamente basófilo, rico em cromatina e praticamente ocupa todo o espaço disponível da célula. Possui estreita franja de citoplasma de cor azul pálido (coloração de Wright), com escassos grânulos azurófilos de cor vermelho púrpura ${ }^{10}$.

Prolinfócitos possuem diâmetro de 9 a $17 \mathrm{~mm}$, com núcleo ovóide; às vezes, possuem um bordo indentado. A cromatina é mais densa e apresenta uma cor púrpura mais intensa que a do linfoblasto. $\mathrm{O}$ quociente núcleo-citoplasma é de 4,5/1. Pode-se ver só um nucléolo, de cor azulada. O citoplasma é maior que o do linfoblasto, 
MANRIQUE, R. \& CARVALHO, E. C. - Imunocitomonitorização em pacientes transplantados cardiacos. Rev. Bras. Cir. Cardiovasc., 5(1): 54-60, 1990.

de cor azul claro ou obscuro e, às vezes, com grânulos azurófilos ${ }^{10}$.

Os linfoblastos possuem diâmetro de 10 a $18 \mathrm{~mm}$. O núcleo ocupa a maior parte da célula, é redondo ou oval. A cromatina tem cor púrpura obscura e forma agregados ao longo da membrana nuclear. $O$ quociente núcleo-citoplasma é de 6/1. Possuem um ou dois nucléolos bem definidos, de cor azul clara. O citoplasma tem cor azul intenso com grânulos; a zona perinuclear é mais clara ${ }^{10}$.

Os exames de CIM feitos no grupo de pessoas normais, candidatos ao transplante cardíaco, pacientes com infecçāo bacteriana ou virose e transplantados cardíacos, somaram um total de 123 e somente no grupo dos transplantados foi feito acompanhamento rotineiro por biopsia miocárdica simultaneamente com os 93 exames de CIM, feitas nesse grupo (Tabela 2). O grupo de pessoas normais (Tabela 1) mostrou uma contagem que variou de zero a cinco prolinfócitos e zero a oito linfoblas-

TABELA 1

ACHADOS DE IMUNOCITOMONITORIZAÇATO EM PESSOAS NORMAIS E CANDIDATOS AO TRANSPLANTE CARD/ACO

\begin{tabular}{|c|c|c|c|}
\hline Identificação & N:PLB & Média & Desvio Padráo \\
\hline \multicolumn{4}{|c|}{ a - Pessoas normais } \\
\hline A.F. & 0 & & \\
\hline L.B. & 0 & & \\
\hline A.E. & 0 & & \\
\hline C.C. & 1 & & \\
\hline R.D. & 1 & & \\
\hline N.G. & 1 & & \\
\hline T.G. & 2 & & \\
\hline A.B. & 2 & & \\
\hline E.T. & 2 & & \\
\hline J.A. & 2 & & \\
\hline A.H. & 2 & & \\
\hline J.R. & 2 & & \\
\hline L.M. & 2 & & \\
\hline C.F. & 3 & & \\
\hline F.F. & 3 & & \\
\hline J.G. & 3 & & \\
\hline A.N. & 3 & & \\
\hline M.J. & 3 & & \\
\hline J.D. & 4 & & \\
\hline E.C. & 4 & & \\
\hline TOTAL & 36 & 1.8 & 1.088 \\
\hline
\end{tabular}

b - Pré-transplantados

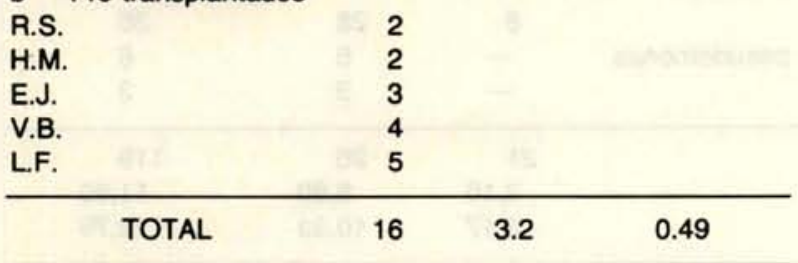

- Não foram encontrados linfoblastos.

PLB = Prolinfócito.
TABELA 2

ACHADOS DE CITOIMUNOMONITORIZAÇÃO FEITA EM PACIENTES TRANSPLANTADOS CARDIACOS*

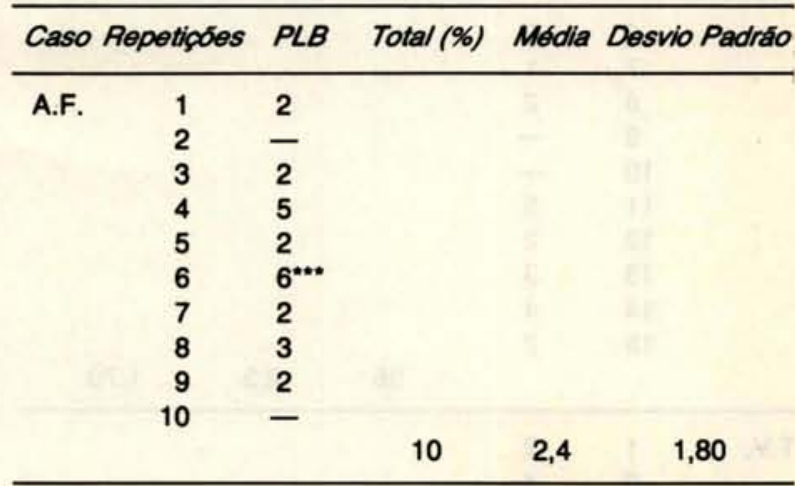

\begin{tabular}{llllll}
\hline A.M. & 1 & 4 & & & \\
& 2 & 2 & & & \\
& 3 & 2 & & & \\
& 4 & 3 & 11 & 2,7 & 1,83 \\
\hline
\end{tabular}

$\begin{array}{rrr}\text { K.H. } & 1 & 3 \\ & 2 & 2 \\ & 3 & 1 \\ 4 & - \\ & 5 & 2 \\ 6 & 3 \\ 7 & - \\ 8 & 2 \\ 9 & - \\ 10 & 2 \\ 11 & 2 \\ 12 & 1 \\ 13 & 1 \\ 14 & 3\end{array}$

$22 \quad 1,5 \quad 1,25$

\begin{tabular}{lll}
\hline K.R. & 1 & 3 \\
& 2 & 1 \\
& 3 & 6 \\
& 4 & 4
\end{tabular}

\begin{tabular}{lll}
\hline O.B. & 1 & 1 \\
& 2 & 2 \\
& 3 & 5 \\
4 & 4 \\
5 & 3 \\
& 6 & -
\end{tabular}

14

3,5

1,80

\begin{tabular}{llllll}
\hline R.S. & 1 & 4 & & & \\
& 2 & 2 & 6 & 3,0 & 1.00 \\
\hline R.F. & 1 & 1 & & & \\
& 2 & 2 & & \\
& 3 & 4 & & \\
& 4 & $6^{* * *}$ & & \\
& 5 & 1 & & \\
\hline
\end{tabular}


MANRIQUE, R. \& CARVALHO, E. C. - Imunocitomonitorização em pacientes transplantados cardiacos. Rev. Bras. Cir. Cardiovasc., 5(1): 54-60, 1990.

TABELA 2 (continuaçăo)

\begin{tabular}{ccccc}
\hline Caso Repetiços & PLB & Total (\%) & Média Desvio Padráo \\
\hline 6 & 2 & & & \\
7 & 1 & & & \\
8 & 2 & & & \\
9 & - & & & \\
10 & - & & & \\
11 & 5 & & & \\
12 & 2 & & & \\
13 & 3 & & \\
14 & 4 & & & \\
15 & 2 & 35 & 2,3 & 1,70 \\
\hline
\end{tabular}

$\begin{array}{lll}\text { T.V. } & 1 & 2 \\ & 2 & 4 \\ & 3 & 6^{* * *} \\ & 4 & 5\end{array}$

17

4,2

1,48

\begin{tabular}{lll}
\hline R.F. & 1 & 2 \\
& 2 & 3 \\
& 3 & 1 \\
& 4 & 1
\end{tabular}

$0,7 \quad 1,7 \quad 0,85$

- Năo foram encontrados linfoblastos; "* Positivo confirmado por biopsia cardiaca; ${ }^{* *}$ Falso positivo.

PLB = Prolinfócito.

tos. Esses resultados serviram de base para os diagnósticos positivos (quando acima de cinco) e negativo (quando abaixo), nos transplantados cardiacos. Havendo sido encontrado, nesse grupo, um indice médio de linfócitos
TABELA 3

RESULTADOS DE CIMS FEITAS NOS TRANSPLANTADOS CARDIACOS SIMULTANEAMENTE COM AS BIOPSIAS

\begin{tabular}{ccccc}
\hline Identif. & CIMs e Biop. & PLB & $\begin{array}{c}\text { Ativaçáo } \\
\text { CIM\% }\end{array}$ & $\begin{array}{c}\text { Resultado } \\
\text { de Biopsia } \\
(-)(+)\end{array}$ \\
\hline A.F. & 10 & 24 & 2,4 & - \\
A.M. & 4 & 11 & 2,7 & - \\
K.H. & 14 & 22 & 1,6 & - \\
K.R. & 4 & 14 & 3,5 & $1+$ \\
O.B. & 6 & 16 & 2,6 & - \\
R.S. & 2 & 6 & 3,0 & - \\
R.F. & 15 & 36 & 2,4 & - \\
T.V. & 4 & 17 & 4,2 & - \\
R.F. & 4 & 7 & 1,7 & - \\
\hline Total & 63 & 161 & 24,7 & \\
Média & & 17,88 & & \\
Desvio Padrão & \multicolumn{5}{c}{2,74} & & \\
\hline
\end{tabular}

(") Não foram encontrados linfoblastos.

PLB = Prolinfócito; $\mathrm{CIM}=$ citoimunomonitorização.

ativados que correspondeu a 1,8\% e, nos pré-transplantados, a $3,2 \%$.

$\mathrm{Na}$ Tabela 2, podem ser vistas as leituras individuais de todas as CIMs feitas no grupo dos transplantados cardíacos, onde diagnosticamos quatro casos positivos para presença de rejeição (com atividade imunológica acima do normal), constatando-se que só um deles foi confirmado positivo nos exames de biopsia. E os outros três, negativos para rejeição, diagnosticados como processo infeccioso em andamento.

TABELA 4

ACHADOS DE IMUNOCITOMONITORIZAÇĀO FEITA EM PACIENTES COM INFECÇĀO BACTERIANA OU VIRAL

\begin{tabular}{|c|c|c|c|c|}
\hline Caso & Diagnóstico & $\begin{array}{c}C I M \\
N: L B\end{array}$ & N:PLB & $\begin{array}{c}\text { Ativação Res. } \\
\% \text { Total }\end{array}$ \\
\hline V.B. & Infecção na incisão cirúrgica com $S$. epidermidis & - & 2 & 2 \\
\hline M.C. & Infecçấo na incisấo cirúrgica com $S$. epidermidis & - & 3 & 3 \\
\hline P.R. & Infecção na incisão cirúrgica com S. epidermidis & - & 3 & 3 \\
\hline A.R. & Infecçăo na incisăo cirúrgica com $S$. epidermidis + e enterococo & 8 & 12 & 20 \\
\hline M.M. & Infecção na incisão cirúrgica com $S$. epidermidis & - & 4 & 4 \\
\hline R.M. & Infecçăo pelo vírus da catapora & 4 & 31 & 35 \\
\hline E.A. & Infecção na ponta do intracat com Klebsiella sp + Proteus mirabilis & 1 & 6 & 7 \\
\hline J.J. & Infecção na traquéia com Klebsiella sp + Proteus mirabilis + & & & \\
\hline & + pseudomonas & 8 & 28 & 36 \\
\hline L.R. & Infecção na incisão cirúrgica com Enterobacter + pseudomonas & - & 6 & 6 \\
\hline M.C. & Abscesso pulmonar com $S$. epidermidis & - & 3 & 3 \\
\hline \multirow{3}{*}{\multicolumn{2}{|c|}{$\begin{array}{c}\text { Total } \\
\text { Média } \\
\text { Desvio Padrăo }\end{array}$}} & 21 & 98 & 119 \\
\hline & & 2,10 & 9,80 & 11,90 \\
\hline & & 3,17 & 10,23 & 12,79 \\
\hline
\end{tabular}

LB $=$ Linfoblatos.

PLB $=$ Prolintócitos. 
Mostramos, na Tabela 3, os resultados globais obtidos de CIMs e biopsias miocárdicas feitas simultaneamente em todos os pacientes transplantados cardíacos.

Encontramos, nos pacientes com infecção (Tabela 4), leituras entre dois e 31 prolinfócitos e de zero a oito linfoblastos. Utilizamos uma média de duas horas para processarmos a amostra e fornecer o resultado final.

\section{DISCUSSĀO}

O método imunocitológico de monitorização (CIM) foi padronizado para diagnosticar a presença de rejeição em transplantados cardíacos tratados com ciclosporina por HAMMER et alii ${ }^{8}$. Em nosso trabalho, procuramos seguir os mesmos moldes desses autores. Segundo eles, a tolerância do sistema imune do paciente transplantado poderia ser avaliada através das mudanças morfológicas que ocorressem no sangue periférico das populaçōes de linfócitos. Esses linfócitos seriam obtidos de um concentrado de células mononucleares que, de acordo com sua aparência morfológica, poderiam ser classificados em pequenos linfócitos normais, prolinfócitos e linfoblastos. E seus resultados poderiam ser confirmados por biopsia miocárdica. A presença desses leucócitos ativados no sangue periférico caracterizaria a ativação do sistema imune, alertando para uma possível crise de rejeição. Ao realizarmos exames de $\mathrm{CIM}$ em pessoas normais, vimos que, em sangue periférico, não foram encontrados linfoblastos (Tabela 1). Em quatro pacientes, constatamos presença de células linfóides ativadas (em média de seis prolinfócitos por paciente). Ao serem confrontados esses resultados com exames de biopsia (Tabela 3), vimos que, em três deles, foi constatado tratar-se de processos infecciosos em andamento. Esses três falsos positivos corresponderam a 6,3\% do total de CIMs realizadas nesse grupo, estando esse resultado bem próximo do encontrado na literatura ${ }^{8}$, que foi de $6,5 \%$. Somente um desses quatro resultados confirmou-se como positivo verdadeiro para presença de rejeição aguda com sinais histológicos segundo critérios de BILLINGHAM ${ }^{3}$.

A constatação de uma ativação acima do normal, com presença de linfócitos " $T$ " 7 , indica que mecanismos imunológicos complexos estão sendo ativados, alertando, assim, para a possibilidade de estar-se iniciando uma crise aguda de rejeição. O processo ocorre quando, dentro dos linfonodos regionais, macrófagos processam antigenicamente os antígenos que estariam presentes na superfície das membranas das células do órgão trans- plantado (antígenos de histocompatibilidade). Eles os apresentam aos linfócitos " $T$ " e "B" que se tornam, assim, sensibilizados contra as células do transplante. Macrófagos liberam interleucinas (IL-1), que facilitam essa sensibilização e estimulam a maturação das células " $T$ ". As IL-1 estimulariam a formação das interleucinas-2 (IL-2). Essas, por sua vez, possuem receptores nos linfócitos "T", que, em presença desses sinais, passariam a exercer as funçōes de células T-Helper. As células "B" são estimuladas a proliferar e produzir anticorpos. Os linfócitos sensibilizados chegam à circulação periférica diretamente ou via ducto toráxico. Ao se encontrarem esses linfócitos com os antígenos presentes no órgão transplantado, iniciam a destruição do enxerto em forma de complexo antígeno-anticorpo (linfócitos T Killer). O sistema complemento é ativado e polimorfonucleares atacam e destroem o endotélio dos vasos. Plaquetas aderem à parede dos vasos. O sistema de coagulação é ativado, ocluindo os vasos ${ }^{1}$.

A validade do CIM pode ser vista, em termos de especificidade e sensibilidade, como um teste predativo bastante sensível para evidenciar reaçōes imunológicas de um modo geral, devido aos resultados obtidos nos diversos grupos, como pacientes com infecção cuja ativação imune foi bem maior $(11,9 \%)$ que a encontrada no grupo normal $(1,8 \%)$ e pré-transplantados $(3,2 \%)$. Isso já estava sendo esperado, visto que as infecçōes (viral e bacteriana) podem ativar o organismo e induzí-lo a fornecer respostas aos antígenos com proliferação de blastos no sangue periférico ${ }^{1}$, o que justificou seu uso como controle positivo para as CIMs. Consideramos como vantagens da $\mathrm{CIM}$ o tempo gasto para a realização dos exames, o qual achamos relativamente curto, seu custo baixo e o caráter não invasivo do exame, quando comparado com as biopsias miocárdicas.

\section{CONCLUSÃO}

A CIM por nós testada mostrou-se de utilidade no diagnóstico de rejeição, ao demonstrar atividade imunológica nos pacientes transplantados cardíacos.

De acordo com os resultados obtidos nas diversas situaçōes a que foi submetido, acreditamos poder indicar seu uso como screening para mostrar se há necessidade ou não de se realizar biopsia miocárdica.

Seu uso também nos pareceu vantajoso, em virtude de se ter seus resultados conhecidos no mesmo dia, ser sensivel e de baixo custo. 
MANRIQUE, R. \& CARVALHO, E. C. - Imunocitomonitorização em pacientes transplantados cardiacos. Rev. Bras. Cir. CardiovasC., 5(1): 54-60, 1990.

RBCCV 44205-107

MANRIQUE, R. \& CARVALHO, E. C. - Immunocytomonitorization in patients submitted to cardiac transplantation. Rev. Bras. Cir. Cardiovasc., 5(1): 54-60, 1990.

ABSTRACT: The immunocytomonitorization technique (CIM - Cytological and Immunologic Monitoring) is based on assessment of changes in the subpopulations of lymphocyte and their precursor cells, while under the acute rejection. The method assesses the precocious activation by counting the number of the lymphocytes normal and actives, lymphoblasts and prolymphocytes (here we state in terms of a set of active lymphocytes). The technique was applied to follow-up and control of activity of cellular immunology in nine patients submitted to cardiac transplantation, twenty normal volunteers, and five patients candidates to cardiac transplantation. We also submitted to the CIM test, in order to obtain the normal range of lymphocytic activity in the brazilian population. Both groups had not antecedents, either infectious or immunological, chronic or acute pictures. Ten patients with acute bacteriological or viral infection had been tested as a positive control. In normal individuals, we found $1,8 \%(+/-1.088)$ of active lymphocytes and $3,2 \%(+/-$ 0,49 ) in candidates for cardiac transplantation. In our experience, values above are indicators of an immunological reactivity related to infection or rejection. Out of the 63 tests performed to the cardiac transplanted patients, four of them were positive, three cases related to infectious complications and one was confirmed as a process of acute graft rejection in progress. The mean time for the CIM execution was about two hours. The method was successful for the immunological diagnosis in transplanted cardiacs, due to its sensibility, low costs and promptness of results.

DESCRIPTORS: immunocytomonitorization in heart transplantation; heart transplantation, human, immunocytomonitorization.

\section{REFERÊNCIAS BIBLIOGRÁFICAS}

1 BELLANTI, J. A. - Immunology. 2. ed. Philadelphia, W.B. Saunders Co., 1985. p. 54-260.

2 BIEBER, P. C.; GRIEPP, R. B.; OYER, P. E.; DAVID, L. A.; STINSON, E. B. - Relationship of rabitt ATG serum clearance rate to circulating T-cell level: rejection onset, and survival in cardiac transplantation. Transpl. Proc., 9: 1031-1033, 1977.

3 BILLINGHAM, M. E. - Some recent advances in cardiac pathology. Hum. Pathol., 10: 377-383, 1979.

4 BISHOP, G.; COSINI, B. A.; VOYNOW, K. N.; WHELCHEL, D. J.; WORTIS, H. H. - Effect of immunosuppressive therapy for renal allografts on the number of circulating sheep red blood cell rosetting cells. Transplaintation, 20: 123-129, 1975.

5 BOYUM, A. - Isolation of mononuclear cells and granulocytes from human blood. Scand. J. Clin. Lab. Invest., 21: (Supl. 9): 77-89, 1968.

6 DORE, C. F. \& BALFOUR, B. M. - A device for preparing cells. Immunology, 9: 403-405, 1965.
7 HALL, M. B.; DORSCH, S.; ROSER, B. - The cellular basis of allograf rejection vivo. J. Exp. Med., 148: 890-902, 1978.

8 HAMMER, C.; REICHENSPURNER, W.; ERTEL, W.; LERSCH, C.; PLAHM, M.; BRENDEL, W.; REICHART, B.; UBERFUHR, P.;WELZ, A.; REBLE, B.; FUNCCIUS, W.; GOREL, M. - Cytological and immunologic monitoring of cyclosporine-treated human heart recipients. Heart Transpl., 3: 228-232, 1984.

9 HERREROS, J.; ARCAS, R.; AZANZA, J.; ERRASTI, P. - Transplante cardlaco. Barcelona, Editorial Científico-Médica, 1983. p. 1-11.

10 PLATT, R. W. - Atlas de hematologia en color. 2 ed. Barcelona, Editorial Jims, 1980. p. 86-87.

11 REICHENSPURNER, W.; ERTEL, W.; HAMMER, C.; LERSCH, B.; UBERFUHR, P.; WELZ, A.; REBLE, B.; KEMKES, B. M.; GOKEL, M. - Immunologic monitoring of heart transplant patients under cyclosporine immunosuppression. Transpl. Proc., 16: 1251-1253, 1984. 